\section{Comparative Evaluation of Carbon Reinforced Polyetherketone Acetabular Cup using Finite Element Analysis}

\author{
Abdal A. ${ }^{* \oplus}$, Noorani R. ${ }^{2}$, Cha G. ${ }^{3}$
}

\begin{abstract}
Background: Patients suffering from osteoarthritis undergo surgery to replace hip joints with hip prosthesis implants. Today most acetabular cups of hip prostheses are made of Ultra-High-Molecular-Weight-Polyethylene. However, these materials acting as acetabular cups of the implant have been recalled since patients have been feeling uncomfortable and abstained from physical activities. A newly introduced material, 30\% Carbon Reinforced Polyetherketone, possess better isotropic mechanical properties and lower wear rates.
\end{abstract}

Objective: The research aims to compare the von-Mises stresses and deformation in static and dynamic loading of Ultra-High Molecular-Weight-Polyethylene to 30\% Reinforced Carbon Fiber Polyetherketone using Finite Element Analysis.

Material and Methods: An analytical study was performed to evaluate material selection and their contact performances of acetabular cups. Four pairs have been analyzed under loading conditions following ASTM F2996-13 and ISO 7206-4 standards. The acetabular cups options are made of 30\% Carbon Reinforced Fiber Polyetherketone or Ultra-High-Molecular-Weight-Polyethylene. Besides, the femoral head and steam options are either Alumina Ceramic or Cobalt Chrome Molybdenum.

Results: The yield strength of Ultra-High-Molecular-Weight-Polyethylene is considerably small, resulting in the acetabular cup to fail when applied to high loading conditions. Carbon Reinforced Polyetherketone with Alumina Ceramic yielded 65\% lower deformation at stumbling phase.

Conclusion: Since the study focuses on linear isotropic material properties, Alumina Ceramic dominates a higher elastic modulus than Cobalt Chrome Molybdenum, nominating it the best fit combination for lower von-Mises stresses, acting on the Carbon Reinforced Polyetherketone acetabular cup.

Citation: Abdal A, Noorani R, Cha G. Comparative Evaluation of Carbon Reinforced Polyetherketone Acetabular Cup using Finite Element Analysis. J Biomed Phys Eng. 2020;10(6):761-770. doi: 10.31661/jbpe.v0i0.2005-1123.

\section{Keywords}

Hip Prosthesis; Carbon Fiber; Acetabular Cup; Dynamic and Static Contact; Finite Element Analysis; Acetabulum

\section{Introduction}

$\mathrm{P}$ hysical wellness involves aspects in a human's life to promote good health and is developed through physical activities such as excising and walking to maintain an optimal health. However, Osteoarthritis (OA) is one of the most common diseases that turns the span of a human's life from physical wellness to physical distress. Total Hip Arthroplasty (THA) is a form of surgery, replacing painful and
${ }^{1} \mathrm{MSc}$, Department of Mechanical Engineering, Loyola Marymount University, Los Angeles, USA

${ }^{2} \mathrm{PhD}$, Department of Mechanical Engineering, Loyola Marymount University, Los Angeles, USA

${ }^{3} \mathrm{PhD}$, The Aerospace

Corporation, 2310 E. El

Segundo Blvd., El Segundo, CA 90245, USA

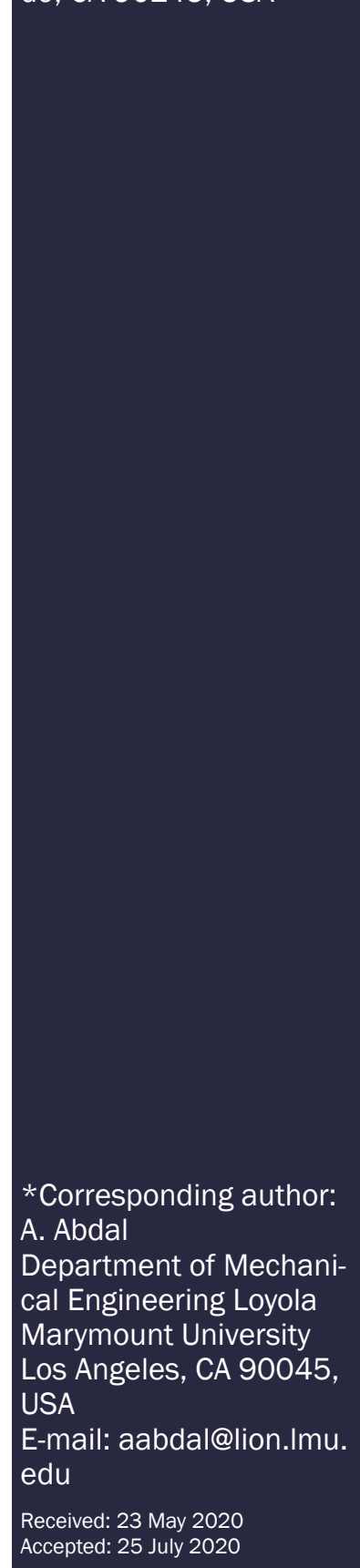


dysfunctional hip joints with orthopedic prostheses. Since OA is widely spread today, doctors have found a remedy to enhance physical wellness of the patient. In 1960, the first hip replacement was performed and recorded as the most successful treatment during the era $[1,2]$. Hip replacement is a surgery where the damaged bone and cartilage are replaced by prosthetic components. Hip prosthetic implants are made up of three major components follows: acetabular component, femoral head, and femoral stem. The acetabular component is the socket bowl shaped component that is considered to refit a patient's resurfaced socket. The acetabular piece is mostly made using metal, plastic polymer, or ceramic material in certain cases. The most common material used as an acetabular cup in THA is Ultra-HighMolecular-Weight-Polyethylene (UHMWPE). UHMWPE possess low-yield strength resulting in the acetabular cup to break at high load conditions and leading to distress for active patients. Among all polymers, Polyethereterketone (PEEK) is a thermoplastic resin that provides higher toughness and better resistances to abrasive wear. 30 Carbon Reinforced/ PEEK (CF/PEEK) laminates show an increase in temperature since the thermoplastic matrix promotes good mechanical and chemical resistance [3].

\section{CF/PEEK as a Biomaterial for Hip Prosthesis}

$30 \mathrm{CF} / \mathrm{PEEK}$ has been used historically in spinal cages, bone fixation screws, and even cardiac leads [4]. Recently, $30 \mathrm{CF} / \mathrm{PEEK}$ is considered as a biomaterial for implants, including knee replacements. The essential benefit of $30 \mathrm{CF} / \mathrm{PEEK}$ as an implant material is that it highly impacts strength to avoid breaking down easily. The elastic modulus of $30 \mathrm{CF} /$ PEEK is identical to that of a human's bone and can withstand prolonged fatigue strain. In addition, $30 \mathrm{CF} / \mathrm{PEEK}$ can be manufactured to match the modulus of both cortical and cancellous bone densities. In 2012, Dickson et al., studied the surface strain measurement in the pelvis using acetabular cups made from cobalt chromium, polyethylene, and $30 \mathrm{CF} / \mathrm{PEEK}$ [5]. The material that produced the closest bone strain to the intact hip in the main load path was $30 \mathrm{CF} / \mathrm{PEEK}$. Therefore, the study concluded that $\mathrm{CF} / \mathrm{PEEK}$ could promote less adverse bone adaption than the current stiffer press-fitted implants in. Also, Wang et al., studied the wear behavior of CF/PEEK bearing couple for both knee replacements and hip prosthesis [6]. The study concluded that $\mathrm{CF} /$ PEEK offers greater tensile strength and is denser, showing that $30 \mathrm{CF} / \mathrm{PEEK}$ material could be a more suitable material for implants after comparing wear rates with polyethylene.

\section{Loading Conditions}

Dynamic loading is time-dependent, which can be accelerated. Static loading is independent of time, resulting in only one response, i.e. displacement. For static condition, the abnormal force of $2300 \mathrm{~N}$ perpendicular to the acetabular cup is followed from ASTM F2996-13 and ISO 7206-4 standards [7, 8]. The abnormal static force is the matter of interest more than normal force of $1200 \mathrm{~N}$ since it gives insights whether $30 \mathrm{CF} / \mathrm{PEEK}$ and UHMWPE acting as an acetabular cup survives the highly exerted force to perform further analysis in dynamic loading condition, which encompasses higher magnitude of forces than static abnormal condition. In dynamic analysis, the magnitude and distribution of stress and displacement during walking is vital to understand the mechanics of an artificial joint [9]. Therefore, a dynamic analysis test is the key point to benefit based on evaluating multiple directional forces to choose the best fit material combination. The gait cycle resembles the dynamic loading condition and is defined as the continuous repetitive pattern of walking or running, which is split into two main phases: stance and swing. El'Sheikh et al., compared the hip prosthesis subjected to a dynamic stumbling load and the peak static load of a similar patient load be- 
Carbon Reinforced Polyetherket one Acetabular Cup

havior [10]. However, many previous studies conducted only evaluate static loads, where the peak loads during normal gait is measured at a specific time. These studies do not consider hip joints exposed to loads such as climbing the stairs, stumbling, or even jumping. Such types of loads are effective loads, resulting hip joints to fail.

\section{Material and Methods}

An analytical study was performed to evaluate material selection for acetabular cups in hip prosthetic devices. The materials used in the analysis are as follows: CoCrMo, Alumina, $30 \mathrm{CF} / \mathrm{PEEK}$, and UHMWPE. CoCrMo and Alumina are the most common used materials for femoral stems and heads in hip implants today and UHMWPE is the superior material used for acetabular cups. $30 \mathrm{CF} / \mathrm{PEEK}$ is the proposed material selection as a surrogate for UHMWPE. The joints are listed as X-Y, where $\mathrm{X}$ is the acetabular cup and $\mathrm{Y}$ is the femoral head and stem. The list is shown as follows:

\section{UHMWPE-CoCrMo \\ II. UHMWPE-Alumina}

\section{III. $30 \mathrm{CF} / \mathrm{PEEK}-\mathrm{CoCrMo}$}

\section{30 CF/PEEK-Alumina}

UHMWPE is a linear semicrystalline thermoplastic polyethylene made by a composite of crystalline and amorphous phases with repeat unit $\left[\mathrm{C}_{4} \mathrm{H}_{4}\right]_{\mathrm{n}}$, where $\mathrm{n}$ denotes the number of polymerizations. Conventional high density polyethene (HDPE) and UHMWPE differ in the number of polymerizations. The higher the number of polymerizations lead to the stiffer and stronger the polyethylene. $30 \mathrm{CF} / \mathrm{PEEK}$ is a thermoplastic semicrystalline polymer in the polyethereterketone (PEEK) family with excellent mechanical and chemical resistance properties. The properties of $30 \mathrm{CF} / \mathrm{PEEK}$ in terms of strength and stiffness can increase by introducing continuous fibers at high concentrations depending on a medical application [11]. Because of its high tensile strength and stiffness of the material, $30 \mathrm{CF} / \mathrm{PEEK}$ can replace UHMWPE acetabular cups in orthopedic applications.

\section{Theory}

Understanding the theory of stresses acting on hip prosthesis and mechanical properties of materials could lead to an innovation that would eventually diminish recalls and guarantee patient satisfaction. There are three vital elements when testing a simulation of a hip prosthesis, including von-Mises stress, deformation, and life expectancy. The von-Mises stress criterion states if a material under a certain load is equal or greater than the elastic yield limit of the same material under simple tension. This study focused on the acetabular cup's survivability that the von-Mises stress criterion is applied to check if the acetabular cup material under a certain load is equal or less than the yield limit. The femoral stem is a brittle material that possess an order of magnitude higher yield limit than the acetabular cup material. The acetabular cup will meet the design limit prior to the femoral stem. The von-Mises stress is a criterion used for yield and stating if yielding occurs in a body for the components of stress, which act on it and are greater than the criterion shown in Equation I:

$$
\sigma_{e}=\sqrt{\frac{\left(\sigma_{1}-\sigma_{2}\right)^{2}+\left(\sigma_{2}-\sigma_{3}\right)^{2}+\left(\sigma_{3}-\sigma_{1}\right)^{2}}{2}}
$$

where $\sigma_{e}$ is the von-Mises stress of the material and $\sigma_{1,2,3}$ are the principal stresses. Failure yield occurs when $\sigma_{e} \geq S_{y}$ and $S_{y}$ is the material's yield strength.

Moreover, mechanical deformation is the physical deformation of a substance from one configuration into another. The relationship between stress and strain is linear in the elastic region and nonlinear in the plastic deformation region. Plastic region is when a deformed material causes change in material's shape and indicates how much it can elongate until it breaks. Only linear isotropic relationship between stress and strain can be simulated to 
Abdal A., Noorani R., Cha G.

study the elastic region. If a material analyzed in software leads to higher von-Mises stress value than the material's yield strength $\left(\sigma_{e} \geq\right.$ $S_{y}$ ), the material conclusively fails, and any further simulation cannot be investigated.

Life expectancy is the most critical element, studied before choosing the best pair. Before failing a hip prosthesis device, the maximum debris is $2 \mathrm{~mm}$. To estimate the wear, Archard's law can be used [12]:

$\mathrm{V}=K_{w} S P_{n}$

where $\mathrm{V}$ is the total volume of debris produced by the device, $\mathrm{S}$ is the sliding distance measured in millimeters $(\mathrm{mm})$, and $P_{n}$ is the normal pressure. Differentiating equation II wear depth (dh) can be calculated:

$$
\begin{gathered}
d V=\Delta A d h=K_{w} \times \sigma \times \Delta A \times d s \\
d h=K_{w} \times \sigma_{f c} \times d s
\end{gathered}
$$

Here the maximum frictional pressure, $\sigma_{f c}$, is measured in megapascal (MPa) and $K_{w}$ is the wear coefficient and a function of material properties, and obtained experimentally. The aim of this paper is to analyze and introduce $30 \%$ Carbon Reinforced Polyetherketone (30 $\mathrm{CF} / \mathrm{PEEK}$ ) as a better new material for acetabular cup in hip implants by implying comparative analysis with today's best material, (UHMWPE), under static and dynamic loading.

\section{Material Properties and Boundary Conditions}

The analytical study focuses on contact analysis of material selection in acetabular cups for hip prosthesis subjected under multiple loading conditions. Linear isotropic material properties chosen for the analysis are shown in Table 1.

The finite element analysis (FEA) setup is based on ASTM F9226-13 and ISO 72064 standards. The setup consists of boundary, contacts, loading, and mesh conditions. There is only one boundary condition that the ASTM F9226-13 includes in the analysis of a hip prosthesis in FEA. Since the stem is buried in the human bone, the boundary condition is considered benign. To save computational effort, the buried part of the stem is removed, and the boundary condition is applied on the bottom of the removed piece. By computing the full body hip prosthesis with the buried stem, the results do not vary. To save computational effort, the buried stem of the fixed position is removed in the analysis.

There are two major contacts in the hip prosthesis design. The first contact tool is between the acetabular cup and the femoral head. Contact body is defined as elements constrained against penetrating the target body. However, target body is element that can penetrate the surface. In rigid-flexible contact, the softer and stiffer materials are selected as the contact and the target body, respectively. UHMWPE and $30 \mathrm{CF} / \mathrm{PEEK}$ are softer materials than Alumina and CoCrMo in terms of density and strength. The acetabular cup is the contact, acting on the femoral head, which is the target body.

The relationship between the contact and target body is frictional. Frictional contact is

Table 1: Linear isotropic material properties $[11,13]$.

\begin{tabular}{ccccc} 
Material & $\begin{array}{c}\text { Young's modulus } \\
(\mathbf{M P a})\end{array}$ & Poisson's ratio & $\begin{array}{c}\text { Yield strength } \\
(\mathbf{M P a})\end{array}$ & $\begin{array}{c}\text { Density } \\
\left(\mathbf{K g} / \mathbf{m}^{\mathbf{3}} \mathbf{)}\right.\end{array}$ \\
\hline UHMWPE & 2200 & 0.33 & 21 & 880 \\
\hline CoCrMo & $230 \times 10^{3}$ & 0.3 & 517 & 7609 \\
\hline Alumina & $375 \times 10^{3}$ & 0.3 & 580 & 872 \\
\hline 30 CF/PEEK & $252 \times 10^{3}$ & 0.379 & 363 & 1306
\end{tabular}


a nonlinear contact that allows the bodies to move freely in normal and tangential directions with respect to a frictional coefficient, $F_{c}$. Bishop et al., studied the relationship between diameter of the acetabular cup and friction coefficient [14]. The study concludes the highest friction factors observed in dry conditions at $33^{\circ}$ cup angle is $F_{c}=0.08$ and $\mathrm{M}=26.5 \mathrm{Nm}$. The acetabular cup is designed with a diameter of $24 \mathrm{~mm}$ to meet clinical requirements used today in total arthroplasty. Since maximum von-Mises stresses and deformations are the points of interest, $F_{c}$ is assigned 0.08 for all iterations in the analysis in both static and dynamic cases.

Another contact was added in the analysis between the femoral head and stem. The assembly is joined by a bonded contact to ensure no movements when analyzing under forces.
Bonded contact is a linear contact with restricted normal and tangential movements and bodies are unable to move freely. The components are bonded together to avoid head displacement from the stem. Figure 1 shows the boundary conditions and contact definitions used in the analysis.

The orientation of the force is placed on the acetabular cup to resemble the ASTM F992613 load model of the circular face of the hip stem trunnion. For static case, the force is chosen as a vector acting normal to the acetabular cup bottom surface direction on the acetabular cup with $\mathrm{F}=2300 \mathrm{~N}$ equivalent to abnormal force from ISO 7206-4. The directional force follows the local coordinates added to the acetabular cup. The abnormal force is the matter of interest when analyzing static case to ensure a bearing couple survives to pursue ana-
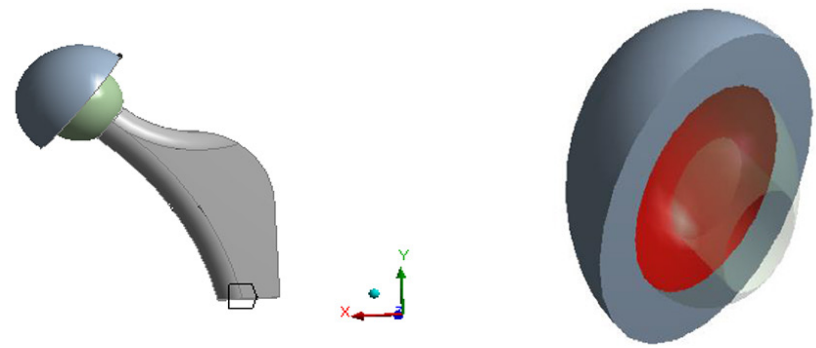

a)

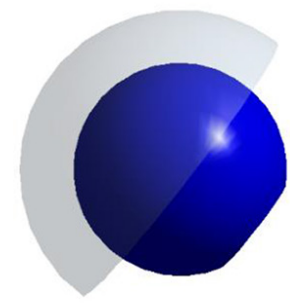

$\therefore$ c)

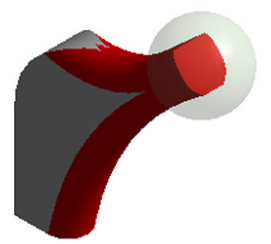

b)
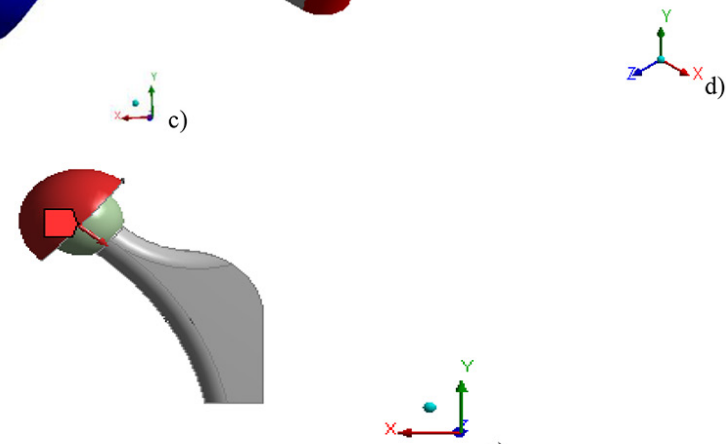

e)

Figure 1: a) Half-body boundary condition b) Contact body acetabular cup c) Target body femoral head d) Bonded contact of femoral head and stem e) Applied normal force 
Abdal A., Noorani R., Cha G.

lyzing further in dynamic condition. If a material fails at an abnormal force, then no further analysis in dynamic condition is required. This is because dynamic forces from the gait cycle varies from one iteration to another, resulting in higher magnitude of forces than the static abnormal force and ASTM F2996-13 only specifies loading condition for static analysis.

Figure 2 shows the dynamics loads from 1-5 seconds in $[\mathrm{x}, \mathrm{y}, \mathrm{z}]$ directions from El'Sheikh et al., where $\mathrm{t}=3$ seconds is the stumbling phase. The stumbling phase is the peak load.
Table 2 shows the forces of dynamic analysis from the gait cycle from Figure 2.

ASTM F2996-13 endorses hexahedral dominant or tetrahedral elements as the types of mesh that is recommended to use when analyzing hip prosthesis in FEA. A mixture of both recommended types of elements are used in the analysis, tetrahedral elements for the acetabular cup and stem and hexahedral dominant for the femoral head.

When studying the mesh convergence of total deformation, as element size increases,

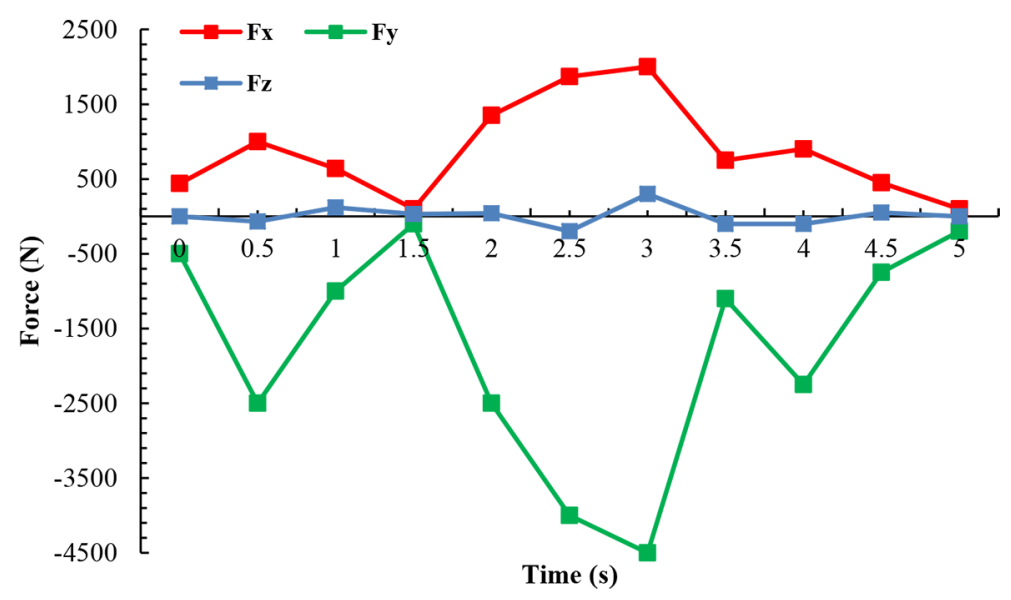

Figure 2: Forces under gait cycle adopted from El'Sheikh [10].

Table 2: Dynamic forces from gait cycle

\begin{tabular}{cccc} 
Time (Seconds) & $\boldsymbol{F}_{\boldsymbol{x}}$ (Newton) & $\boldsymbol{F}_{\boldsymbol{y}}$ (Newton) & $\boldsymbol{F}_{\mathbf{z}}$ (Newton) \\
\hline 0 & 440 & 0 & -500 \\
\hline 0.5 & 1000 & -70 & -2500 \\
\hline 1 & 640 & 120 & -1000 \\
\hline 1.5 & 100 & 30 & -100 \\
\hline 2 & 1350 & 40 & -2500 \\
\hline 2.5 & 1870 & -200 & -4000 \\
\hline 3 & 2000 & 300 & -4500 \\
\hline 3.5 & 750 & -100 & -1100 \\
\hline 4 & 900 & -100 & -2250 \\
\hline 4.5 & 450 & 50 & -750 \\
\hline 5 & 100 & 0 & -200
\end{tabular}


the corresponding total deformation increases. The smaller the element size, the closer the values are i.e. element size $0.7-0.9 \mathrm{~mm}$. For element increments of $0.1 \mathrm{~mm}, 0.7-0.9 \mathrm{~mm}$ have an average of $3.83 \%$ difference in total deformation results, where $0.9 \mathrm{~mm}$ is the lowest percent difference of $3.68 \%$ and is chosen as an element body size for the analysis.

\section{Results}

In static loading condition, the results for both acetabular cups analyzed varied in stresses. UHMWPE von-Mises stress result was 22.2 MPa and is higher than the material's yield strength. Following the inequality, $\sigma_{e} \geq$ $S_{y}$, UHMWPE stress was $22.2 \mathrm{MPa}>21 \mathrm{MPa}$ and is concluded as unsafe to use. Hooke's law is limited to elastic region and if a material fails the criteria, then the material is assumed to be plastically deforming. $30 \mathrm{CF} / \mathrm{PEEK}$ vonMises stress was higher than UHMWPE but satisfies the survivability criteria because of its superior yield strength $21.8 \mathrm{MPa}<363 \mathrm{MPa}$.

The maximum von-Mises stress occurs on the surface edge of the acetabular cup where frictional relationship exist between the contact and target bodies. Based on the von-Mises stresses of the acetabular cups, UHMWPE is unable to survive under the static loading condition and deforms because of its low yield strength. In result, $30 \mathrm{CF} / \mathrm{PEEK}$ is the only option nominated as safe. $30 \mathrm{CF} / \mathrm{PEEK}$-Alumina and $30 \mathrm{CF} / \mathrm{PEEK}-\mathrm{CoCrMo}$ are analyzed under dynamic loading in $F_{x}, F_{y}, F_{z}$ from 1-5 seconds under ASTM F9926-13 conditions. The forces are added as components of $x, y$, and $z$ to follow the local coordinates acting on the acetabular cup. Also, the total deformation are analyzed in iterations from 1-5 seconds to evaluate the performance during the gait cycle.

$30 \mathrm{CF} / \mathrm{PEEK}$ is the only option to evaluate under dynamic loading condition and the results from 1-5 seconds are summarized in Table 3, where $\mathrm{t}=3$ seconds is the stumbling phase.

As shown from dynamic von-Mises stress
Table 3: Dynamic von-Mises stress of 30 Carbon Reinforced (CF)/Polyethereterketone (PEEK) acetabular cup

\begin{tabular}{cc} 
Time (s) & von-Mises Stress $(\mathbf{M P a})$ \\
\hline 1 & 15.4 \\
\hline 2 & 16.3 \\
\hline 3 & 28.3 \\
\hline 4 & 13.9 \\
\hline 5 & 1.3
\end{tabular}

graph from Figure 3, from 1 - 3 seconds the forces increase in all $[\mathrm{x}, \mathrm{y}, \mathrm{z}]$ directions causing the von-Mises to increase proportionally. During stumbling phase, the highest value of von-Mises stress is recorded as 28.3 MPa, lower than $30 \mathrm{CF} / \mathrm{PEEK}$ yield strength. Any time beyond 3 seconds, the forces decrease and so do the von-Mises stresses.

The deformation of $30 \mathrm{CF} / \mathrm{PEEK}$-Alumina and $30 \mathrm{CF} / \mathrm{PEEK}-\mathrm{CoCrMo}$ are analyzed in dynamic loading. The pair with the least deformation will be nominated as the best-pair option. Table 4 summarizes the total deformation of the two pairs under dynamic loading condition.

The results varied between $30 \mathrm{CF} / \mathrm{PEEK}$ Alumina and $30 \mathrm{CF} / \mathrm{PEEK}-\mathrm{CoCrMo}$ with an average of $0.39 \mathrm{~mm}$ higher for CoCrMo combination and approximately twice the average during stumbling phase. CoCrMo has lower elastic modulus than Alumina resulting with higher deformation.

\section{Life Expectancy and Wear Results}

In a complete walking cycle, the hip joint rotates $80^{\circ}$ [15]. The femoral head of the radius for this present study is $12 \mathrm{~mm}$. For a total hip, rotation in one cycle is equal to $80^{\circ}$ and the sliding distance is the acetabular cup head radius multiplied by the rotation angle.

Sliding distance $=$ Head radius $\times$ Rotation angle Sliding distance $=12 \mathrm{~mm} \times 1.396=16.75 \mathrm{~mm}$

In this demonstration, $\mathrm{CF} / \mathrm{PEEK}$-Alumina at stumbling phase is calculated using frictional 
Abdal A., Noorani R., Cha G.

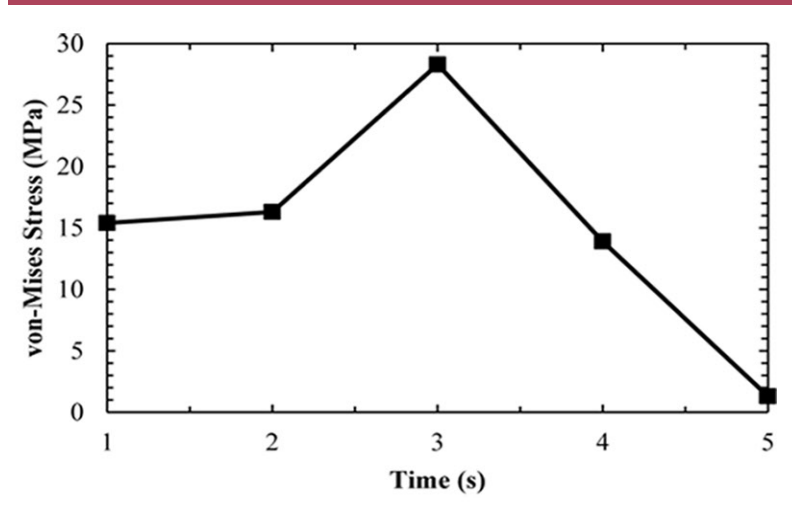

a)
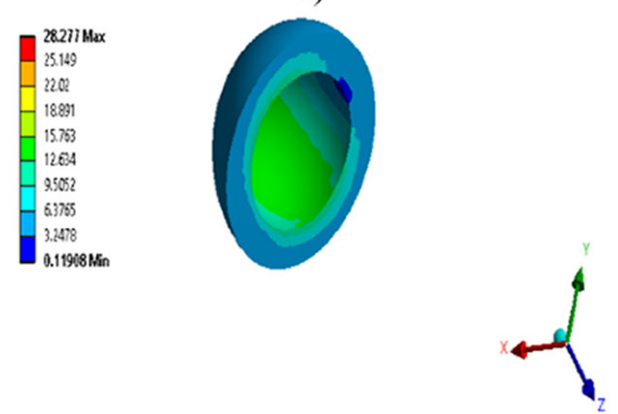

b)

Table 4: Total deformation results of dynamic loading under gait cycle

\begin{tabular}{ccc} 
Time (s) & $\begin{array}{c}\text { 30 CF/PEEK- } \\
\text { CoCrMo (mm) }\end{array}$ & $\begin{array}{c}\text { 30 CF/PEEK-Alu- } \\
\text { mina (mm) }\end{array}$ \\
\hline 1 & 0.84 & 0.53 \\
\hline 2 & 0.93 & 0.58 \\
\hline 3 & 1.69 & 1.02 \\
\hline 4 & 0.91 & 0.51 \\
\hline 5 & 0.24 & 0.08
\end{tabular}

contact pressure $\sigma_{f c}$. Now the wear depth (dh) can be calculated using Equation III. To obtain the frictional coefficient, a pin-on-disc experiment is required to find $K_{w}$. Scholes et al., studied the Carbon Reinforced Polyetherketone and OPTIMA Alumina Ceramic $(\mathrm{CF} /$ PEEK OPTIMA) articulating against alumina ceramic on pin-on-desk testing and for the four tests the average of wear coefficient is the $K_{w}=19.35 \times 10^{-8} \mathrm{~mm}^{3} / \mathrm{Nm}$ [16].

Wear depth $=19.35 \times 10^{-8} \mathrm{~mm}^{3} / \mathrm{Nm} \times 642$ $\mathrm{MPa} \times 16.75 \mathrm{~mm}=2.08 \mathrm{~mm} /$ cycle assuming if an average person takes one million steps over a year, the wear is found to be $0.295 \mathrm{~mm} /$ year. The allowable wear of a hip prosthesis is $2 \mathrm{~mm}$. The life expectancy is always approximately 1 year for a hip prosthesis under stumbling phase i.e. walking the stairs. The assumption is that the person is walking the stairs for $24 \mathrm{~h}$ and 365 days of the year for in 10 million steps, the hip will fail in one year. A person would not climb the stairs for $24 \mathrm{~h}$ of a day, 365 days of a year, continuously. Evaluating the design choice combination in abnormal cases would give insights how the hip prosthesis could survive such conditions. To extend life expectancy, a larger radius of the acetabular cup is recommended.

Figure 3: a) Dynamic loading representation of von-Mises stress b) Von-mises stress of acetabular cup at iteration time 1 second c) Von-mises stress of acetabular cup at stumbling phase d) Von-Mises stress at end of gait cycle

\section{Discussion}

A comparison study is performed between the proposed hip prosthesis following ASTM F2996-13 standards and authors who studied only parts of the hip prosthesis without fol- 
lowing any standards. Stumbling phase is a result of interest at highest peak stress to evaluate if a combination survives. Shankar et al., concluded that the best options to choose are UHMWPE-CoCr and UHMWPE-Alumina and the difference between both combinations is only $10 \mathrm{MPa}$ higher for $\mathrm{CoCr}$ [17]. Varghese concluded CF/PA 12 and CF/PEEK are both good options when compared to the human bone von-Mises stress. CF/PA 12 was closer [18]. Von-Mises stresses at stumbling for Shankar et al., and Varghese are compared to $30 \mathrm{CF} / \mathrm{PEEK}$-Alumina in the bar graph below (Figure 4).

\section{Conclusion}

It is found that $30 \mathrm{CF} / \mathrm{PEEK}$ performs better as an acetabular cup than UHMWPE. UHMWPE has a low yield strength causing the material to be brittle when analyzing large forces. UHMWPE deforms at abnormal $\mathrm{F}=2300 \mathrm{~N}$ from ISO 7206-4 by resulting with von-Mises stress larger than the material's yield strength. In other hand, $30 \mathrm{CF} / \mathrm{PEEK}$ survives the abnormal force due to its higher yield strength. In reference to total deformation, $30 \mathrm{CF} / \mathrm{PEEK}$ Alumina pair always deforms lower than $30 \mathrm{CF} / \mathrm{PEEK}-\mathrm{CoCrMo}$ due to larger elastic modulus. Even if both Alumina and CoCrMo combinations survived, the lower deformed couple is a better and safer option to choose. CoCrMo is negated since metal alloys tend to cause inflammation in the human body after a while. In conclusion, $30 \mathrm{CF} / \mathrm{PEEK}$-Alumina is the best pair for a hip prosthesis to ensure patient's comfortability.

$30 \mathrm{CF} / \mathrm{PEEK}$-Alumina has been observed as bearing couple materials under static ASTM F9226-13 and dynamic condition of the gait cycle by FEA. After gaining confidence of the materials combination, a vivo test known as AMTI hip wear simulation test is required to meet the ISO 14243-1 standard before taking into consideration the bearing couple as "bestfit" for hip prosthesis joints in surgical procedures.

\section{Conflict of Interest}

None

\section{References}

1. AlHW. Osteoarthritis Snapshot, What Is Osteoarthritis? Australian Institute of Health and Welfare. 2018 [cited 2018 July 24]. Available from: www. aihw.gov.au/reports/chronic-musculoskeletalconditions/osteoarthritis/contents/what-is-osteoarthritis.

2. CPMC. Osteoarthritis: Risk Report. Coriell Personalized Medicine Collaborative. 2018 [cited 2018 December 15]. Available from: https://cpmc.coriell.org/v/Report/Demo/Osteoarthritis/DemoNat.

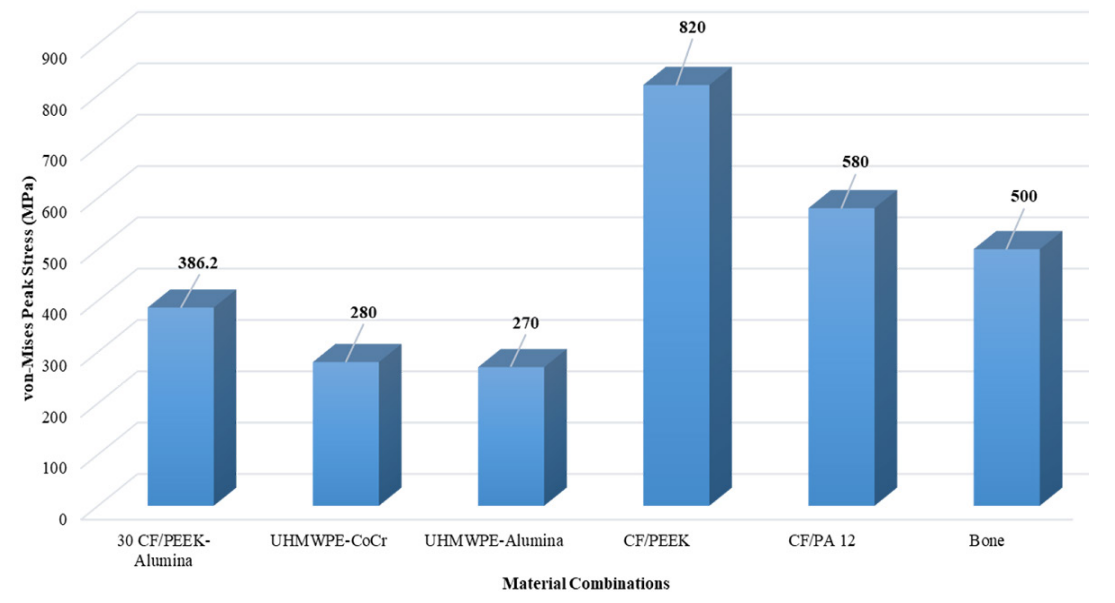

Figure 4: Comparison Analysis Results with Shankar et al., [17] and Varghese [18] for Different Materials During Stumbling Phase 
Abdal A., Noorani R., Cha G.

3. Stuart G. CFR PEEK Composite for Surgical Applications. MDDI Online, Medical Device and Diagnostic Industrt. 2017 [cited 2017 Aug 7]. Available from: www.mddionline.com/cfr-peekcomposite-surgical-applications.

4. Brockett CL, Carbone S, Fisher J, Jennings LM. PEEK and CFR-PEEK as alternative bearing materials to UHMWPE in a fixed bearing total knee replacement: an experimental wear study. Wear. 2017;374:86-91. doi: 10.1016/j. wear.2016.12.010.

5. Dickinson AS, Taylor AC, Browne M. The influence of acetabular cup material on pelvis cortex surface strains, measured using digital image correlation. Journal of Biomechanics. 2012;45(4):719-23. doi: 10.1016/j.jbiomech.2011.11.042.

6. Wang A, Lin R, Stark C, Dumbleton JH. Suitability and limitations of carbon fiber reinforced PEEK composites as bearing surfaces for total joint replacements. Wear. 1999;225:724-7. doi: 10.1016/ S0043-1648(99)00026-5.

7. ISO. Implants for surgery - Partial and total hip joint prostheses - Part 4: Determination of endurance properties and performance of stemmed femoral components. [cited 2015 September 24]. Available from: https://www.iso.org/standard/42769.html.

8. American Society for Testing and Materials. Standard practice for finite element analysis (FEA) of non-modular metallic orthopaedic hip femoral stems. ASTM International; 2013.

9. Jiang HB. Static and dynamic mechanics analysis on artificial hip joints with different interface designs by the finite element method. Journal of Bionic Engineering. 2007;4(2):123-31. doi: 10.1016/S1672-6529(07)60024-9.

10. El'Sheikh HF, MacDonald BJ, Hashmi MS. Finite element simulation of the hip joint during stumbling: a comparison between static and dynamic loading. Journal of Materials Processing Technology. 2003;143:249-55. doi: 10.1016/S09240136(03)00352-2.
11. Shankar S, Prakash L, Kalayarasan M. Finite element analysis of different contact bearing couples for human hip prosthesis. Int J Biomed Eng Technol. 2013;11(1):66-80. doi: 10.1504/ IJBET.2013.053712.

12. Wu JS, Hung JP, Shu CS, Chen JH. The computer simulation of wear behavior appearing in total hip prosthesis. Computer Methods and Programs in Biomedicine. 2003;70(1):81-91. doi: 10.1016/ S0169-2607(01)00199-7.

13. The Online Materials Information Resource. MatWeb, Victrex Polymer Solutions. [cited 2019 January 15]. Available from: www.matweb.com/ search/DataSheet.aspx?MatGUID=e0993de8cfa74 798876b7883382af4dd\&ckck=1.

14. Bishop NE, Hothan A, Morlock MM. High Friction Moments in Large Hard-on-Hard Hip Replacement Bearings in Conditions of Poor Lubrication. J Orthop Res. 2013;31(5):807-13. doi: 10.1002/ jor.22255. PubMed PMID: 23239536.

15. Desai C, Hirani H, Chawla. Life Estimation of Hip Joint Prosthesis. J Inst Eng India Ser C. 2015;96(3):261-7. doi: 10.1007/s40032-0140159-4.

16. Scholes SC, Unsworth A. The Wear Properties of CFR-PEEK-OPTIMA Articulating against Ceramic Assessed on a Multidirectional Pin-Onplate Machine. Proc Inst Mech Eng H. 2007;221(3):281-9. doi: 10.1243/09544119JEIM224. PubMed PMID: 17539583.

17. Shankar S, Manikandan M. Dynamic Contact Analysis of Total Hip Prosthesis During Stumbling Cycle. Journal of Mechanics in Medicine and Biology. 2014;14(3):1-13. doi: 10.1142/ S0219519414500419.

18. Varghese V. Finite Element Based Design of Hip Joint Prosthesis. Department of Biotechnology \& Medical Engineering National Institute of Technology Rourkela-769008; 2015. Available from: https://www.researchgate.net/publication/288303844_Finite_element_based_design_ of_hip_joint_prosthesis. 